Psychological Medicine, 1998, 28, 109-126. Printed in the United Kingdom

(C) 1998 Cambridge University Press

\title{
Prevalence of mental disorders and psychosocial impairments in adolescents and young adults
}

\author{
H.-U. WITTCHEN, ${ }^{1}$ C. B. NELSON AND G. LACHNER \\ From the Max Planck Institute of Psychiatry, Clinical Psychology and Epidemiology Unit, Munich, Germany
}

\begin{abstract}
Background. As part of a longitudinal study, prevalence findings of DSM-IV disorders are presented for a random sample of 3021 respondents aged 14 to 24 , with response rate $71 \%$.

Method. Assessment included various subtypes of disorders, subthreshold conditions and disorders that have only rarely been studied in other epidemiological surveys. The computer-assisted MunichComposite International Diagnostic Interview (M-CIDI) was used to derive DSM-IV diagnoses.

Results. Substance disorders were the most frequent (lifetime $17.7 \% ; 12$-month $11.4 \%$ ), with abuse being considerably more frequent than dependence. Other mental disorders had a lifetime prevalence of $27.5 \%$ (12-month, $17.5 \%$ ) with depressive disorders $(16.8 \%)$ being more frequent than anxiety disorders $(14.4 \%)$. Eating disorders $(3.0 \%)$ and threshold somatoform disorders $(1 \cdot 2 \%)$ were rare disorders. Subthreshold anxiety and somatoform disorders, however, were more frequent than threshold disorders. Prevalence of disorders was equally high for males and females, although specific disorder prevalence varied significantly by gender. The co-occurrence of disorders (co-morbidity) was substantial and was significantly related to greater reductions in work productivity and increased rates of professional helpseeking behaviour.

Conclusions. Findings underline that mental disorders in young adults are frequent and impairing, limiting work and education ability and social interaction. Given the fact that adolescents and young adults are in a key phase of socialization in terms of professional career and interpersonal relationships, our findings indicate a considerable risk potential for an accumulation of complicating factors and future chronicity. This paper is the first report of this ongoing longitudinal study about early developmental conditions of mental disorders.
\end{abstract}

\section{INTRODUCTION}

Using standardized diagnostic criteria and structured interviews, recent surveys have demonstrated that a large proportion of the adult general population experiences mental disorders at some time in their life (Angst \& DoblerMikola, 1985; Wittchen et al. 1987, 1992; Robins \& Regier, 1991; Kessler et al. 1994) and among respondents meeting criteria for any diagnosis there is substantial and significant diagnosis cooccurrence both within and between major classes of disorder (Boyd et al. 1984; Regier et al. 1990; Kessler et al. 1994; Merikangas et al. 1996; Wittchen, 1996a). Additional data on the

1 Address for correspondence: Professor Hans-Ulrich Wittchen, Max Planck Institut für Psychiatrie, Clinical Institute, Kraepelinstrasse 2, 80804 München, Germany. age of first onset of specific symptomatology has also allowed for the characterization of diagnosis incidence across the lifecourse as well as temporal patterns of diagnosis co-occurrence (Burke et al. 1990; Robins \& Regier, 1991; Magee et al. 1996; Wittchen, 1996a). These studies indicate that while the onset of mental disorders can occur at anytime across the lifecourse, certain mental disorders such as phobic disorders begin to emerge in childhood while others such as major depression and generalized anxiety disorders (GAD) emerge later in adolescence and substance dependence characteristically emerge for the first time in the late teens. Adult epidemiological surveys also suggest that more than one-third of all adolescents already suffer from mental disorders, and that a considerable degree of co-morbidity (defined as the presence 
of more than one disorder), might be already present at this young age. These conclusions, however, should be taken cautiously because the above mentioned studies all covered a broad age range of respondents from as early as adolescence to old age (ECA oldest age groups $>85$ ). We can expect that recall of symptomatology that may have occurred many years ago in childhood is incomplete and subject to recall bias. Given the potentially serious consequences of early adolescent disorders for the respondents future psychosocial and health development, there is clearly a need to investigate the magnitude, the risks and the developmental patterns of adolescent psychopathology.

Some of this evidence seems to be available from the child psychiatric literature. Several longitudinal epidemiological surveys of children and adolescents have been published in the last decade most of which, however, can not be directly compared to the adult community studies cited above. Some of these studies have been conducted with children younger than 14, most used different sampling strategies, different diagnostic classifications, different diagnostic instruments, varying threshold definitions for case finding and covered a different scope of disorders. In addition, there seems to be considerable variability in findings (Boyle et al. 1987; Bird et al. 1988). For example, the prospective Dunedin-New Zealand birth cohort study (McGee et al. 1992) reported a prevalence of $2.3 \%$ for depressive disorders for 15 -yearolds using the Diagnostic Interview Schedule for Children (DISC; Costello et al. 1982) and at age 18 a prevalence of major depressive episode of $17 \%$ (Feehan et al. 1997) using a modified version of the Diagnostic Interview Schedule (DIS; Robins et al. 1981). Bird et al. (1988) used a household sample of children aged from 4 to 16 in a two-stage design and found with the DISC a DSM-III prevalence of $8.7 \%$ in 14 to 16 year old adolescents. Garrison et al. (1992) estimated the prevalence of depressive disorders in 12 to 14 year olds to be $9.0 \%$ in males and $8.9 \%$ in females (major depression) and $8 \%$ (males) and 5\% (females) for dysthymia. This study used a two-stage design with the Schedule for Affective disorders and Schizophrenia (KSADS, Chambers et al. 1985) administered by a nurse as the diagnostic instrument. Lewinsohn et al. $(1993,1994,1995)$ studied high school students in a follow-up study (1-year time interval) with the K-SADS and reported point prevalence for depressive disorders from 3.2 to $3.8 \%$ and high lifetime estimates of 20.0 to $25.3 \%$. The variance of these findings probably does not reflect true differences, but is due rather to differences in case definition, diagnostic instruments and sample composition. Irrespective of these differences and the scope of diagnoses covered in each of the studies, however, there seems to be some consensus that both prevalence and co-morbidity of mental disorders in adolescents is considerable. Lewinsohn et al. estimate that $42.8 \%$ of adolescents are affected by at least one disorder (more than one-third was co-morbid), McGee et al. (1992) reported a prevalence of $42 \%$, Bird et al. (1988) arrived at conservative estimates for moderate and severe psychopathology of $15.8 \%$ and the findings of Garrison et al. (1992, see also Cuffe et al. 1995) suggested an overall prevalence of $20 \%$, excluding substance use disorders, with considerable overlap between affective and nonaffective disorders.

\section{Objectives}

This paper reports findings from the baseline interviews of a prospective longitudinal study, the Early Developmental Stages of Psychopathology (EDSP), conducted among adolescents and young adults from 14 to 24 years of age living in metropolitan Munich, Germany. This study gives the opportunity for prospective follow-up during adolescence and early adulthood when the risk for incident anxiety, affective disorders, substance disorders and the development of co-morbidity is obviously highest. Because the emphasis of the project is the study of developmental patterns of psychopathology from early adolescence to early adulthood, focus is laid upon the assessment of adult mental disorders. Childhood disorders (conduct, attention deficit disorders, etc.) as potentially important precursor conditions for subsequent psychopathology are being assessed in a separate part of the project by interviewing the parents of our respondents; these findings will be reported in a separate publication. Important features of the EDSP study include: an interview that is based on a modified version of the Composite International Diagnostic Interview (CIDI; WHO 1990) adapted to evaluate 
DSM-IV (APA, 1994) and ICD-10 (WHO 1991) research diagnostic criteria; the assessment of a broader range of diagnoses and syndromes than previous surveys; and the use of memory aid techniques introduced by the National Comorbidity survey (Kessler et al. 1994) to improve the recall for onset and disabilities associated with past episodes of disorders. In addition, the EDSP sample of 14 to 24 year olds has been chosen to minimize the effect of recall bias while maximizing its utility in estimating baseline prevalence and estimating incidence in our subsequent waves. The following objectives are addressed.

1 What is the lifetime and 12-month prevalence of DSM-IV mental disorders among young adults and how frequent is co-morbidity?

3 Which sociodemographic factors are associated with mental disorders among young adults?

4 How impairing are these disorders in terms of interference with social roles and productivity?

5 How frequently do young adults with mental disorders use health care services?

\section{METHOD}

The Early Developmental Stages of Psychopathology (EDSP) study is a research programme funded by the German Ministry of
Research and Technology, designed to collect data on the prevalence, risk factors, co-morbidity and course of mental disorders with specific emphasis on substance use disorders. The overall design of the study is prospective, it consists of a baseline survey and two follow-up surveys at approximately 15 and 30 months after the baseline. Separate personal interviews with the respondents' parents are currently being carried out to evaluate childhood development and childhood disorders together with family genetic variables (for a full description see Wittchen et al. 1997a). The follow-up surveys will investigate symptom and diagnosis progression, incidence and remission as well as help-seeking and the development of impairments. The results presented here are from the first wave of data collection, which was conducted from January to July to 1995.

\section{Sample}

The sample was drawn from the 1994 Bavarian government registry of residents in metropolitan Munich with all registrants expected to be from 14 to 24 years of age during the first half of 1995 being eligible for selection. Munich is the capital of Bavaria (population 2.6 million) with a high proportion of the population being employed in the educational and service settings $(32 \%)$ followed by manufacturing industries $(22 \%)$ and trade $(18 \%)$. Similar to other German

Table 1. Demographic distribution of the sampled population, the respondents unweighted and weighted, and the population in metropolitan Munich

\begin{tabular}{|c|c|c|c|c|c|c|c|c|c|}
\hline & \multicolumn{2}{|c|}{ Sample } & \multicolumn{3}{|c|}{ Respondents unweighted } & \multicolumn{2}{|c|}{ Respondents weighted } & \multicolumn{2}{|c|}{$\begin{array}{c}\text { Metropolitan Munich } \\
\text { in } 1990\end{array}$} \\
\hline & $N$ & $\%$ & $N$ & $\% \mathrm{~S}^{*}$ & $\% \mathrm{R} \dagger$ & $N$ & $\%$ & $N$ & $\%$ \\
\hline Total & 4263 & $100 \cdot 0$ & 3021 & $70 \cdot 9$ & $100 \cdot 0$ & 3021 & $100 \cdot 0$ & 110363 & $100 \cdot 0$ \\
\hline Men, total & 2129 & $49 \cdot 9$ & 1533 & $72 \cdot 0$ & $50 \cdot 7$ & 1493 & $49 \cdot 4$ & 54458 & $49 \cdot 3$ \\
\hline $14-15$ & 632 & $14 \cdot 8$ & 470 & $74 \cdot 3$ & $15 \cdot 6$ & 241 & $8 \cdot 0$ & 8034 & $7 \cdot 3$ \\
\hline $16-17$ & 331 & $7 \cdot 8$ & 244 & $73 \cdot 6$ & $8 \cdot 1$ & 223 & $7 \cdot 4$ & 8128 & $7 \cdot 4$ \\
\hline $18-19$ & 320 & $7 \cdot 5$ & 241 & $75 \cdot 4$ & $8 \cdot 0$ & 221 & $7 \cdot 3$ & 7946 & $7 \cdot 2$ \\
\hline $20-21$ & 355 & $8 \cdot 3$ & 243 & $68 \cdot 5$ & $8 \cdot 0$ & 253 & $8 \cdot 4$ & 9760 & $8 \cdot 8$ \\
\hline $22-24$ & 497 & $11 \cdot 6$ & 335 & $67 \cdot 5$ & $11 \cdot 1$ & 554 & $18 \cdot 3$ & 20590 & $18 \cdot 7$ \\
\hline Women, total & 2134 & $50 \cdot 1$ & 1488 & $69 \cdot 7$ & $49 \cdot 3$ & 1528 & $50 \cdot 6$ & 55905 & $50 \cdot 7$ \\
\hline $14-15$ & 588 & $13 \cdot 8$ & 433 & $73 \cdot 6$ & $14 \cdot 3$ & 234 & $7 \cdot 7$ & 7922 & $7 \cdot 2$ \\
\hline $16-17$ & 326 & $7 \cdot 7$ & 248 & $76 \cdot 0$ & $8 \cdot 2$ & 222 & $7 \cdot 3$ & 7913 & $7 \cdot 2$ \\
\hline $18-19$ & 314 & $7 \cdot 4$ & 219 & $69 \cdot 6$ & $7 \cdot 2$ & 224 & $7 \cdot 4$ & 8568 & $7 \cdot 8$ \\
\hline $20-21$ & 393 & $9 \cdot 2$ & 255 & $64 \cdot 8$ & $8 \cdot 4$ & 295 & $9 \cdot 8$ & 10638 & $9 \cdot 6$ \\
\hline $22-24$ & 520 & $12 \cdot 2$ & 333 & $64 \cdot 1$ & $11 \cdot 0$ & 553 & $18 \cdot 3$ & 20864 & $18 \cdot 9$ \\
\hline
\end{tabular}

* Percentage of sample

$\dagger$ Percentage of respondents. 
metropolitan areas, there is a considerable proportion of foreign guest workers/migrants $(21 \%)$. Compared with other cities in Germany, only a relatively small proportion of Munich's residents are unemployed $(6 \%)$.

Because the study is designed as a longitudinal panel with special interest in the development of substance disorders, 14 to 15 year olds were sampled at twice the probability of those aged 16 to 21 years and 22 to 24 year olds were sampled at half this probability. From the total of 4809 sampled individuals, 4263 were located and determined to be eligible for the study. Sampled individuals who were not located were disproportionately older and uncontactable because they had either moved outside the metropolitan Munich area in the time interval between their registration and the beginning of the study in $1995(8.8 \%)$ or could not be associated with the listed address during the field work period $(2.4 \%)$. From the 4263 individuals a total of 3021 interviews were completed resulting in a response rate of $71 \%$. In addition, partial information was obtained on an additional $6 \cdot 2 \%$, these findings will not be reported here. Refusal to participate $(18.2 \%)$ was by far the most frequent reason for non-response followed by a reported lack of time $(3 \cdot 3 \%)$, failure to contact anyone in the identified household $(3.1 \%)$ and failure to contact the sampled individual in an identified household $(3.0 \%)$. Demographically, non-response increased with age, especially among women whose nonresponse rates were slightly higher than those of men among individuals $>18$ years of age (see Table 1). The slightly higher proportion of refusals among women was due to increased reports of lack of time, failure to contact anyone in the household and failure to contact the sampled individual. Because previous studies have found non-response and attrition to be significantly higher among persons with psychiatric disorders (Allgulander 1989; Eaton et al. 1994; Kessler et al. 1994), future analyses will examine this area in more detail.

To account for the differential sampling probabilities, oversampling of persons expected to be 14 to 15 years of age at interview and undersampling of 21 to 24 year olds, individuals who were not located and non-response, the data have been adjusted by age, sex and geographic location to match the distribution of
Table 2. Distribution (\%) of sociodemographic variables

\begin{tabular}{|c|c|c|c|}
\hline & Total & Men & Women \\
\hline \multicolumn{4}{|l|}{ Type of education } \\
\hline Hauptschule & $11 \cdot 0$ & $12 \cdot 5$ & $9 \cdot 5$ \\
\hline Realschule & $18 \cdot 4$ & $15 \cdot 4$ & $21 \cdot 2$ \\
\hline Fachhochschule & $4 \cdot 9$ & $5 \cdot 4$ & $4 \cdot 3$ \\
\hline Gymnasium & $30 \cdot 3$ & $29 \cdot 3$ & $31 \cdot 3$ \\
\hline University & $35 \cdot 0$ & $37 \cdot 0$ & $33 \cdot 1$ \\
\hline Drop out & $0 \cdot 5$ & $0 \cdot 4$ & $0 \cdot 6$ \\
\hline \multicolumn{4}{|l|}{ Living arrangement } \\
\hline w/ Parents & $63 \cdot 6$ & $68 \cdot 5$ & $58 \cdot 8$ \\
\hline Alone & $23 \cdot 1$ & $21 \cdot 8$ & $24 \cdot 4$ \\
\hline w/ Partner & $9 \cdot 5$ & $7 \cdot 9$ & $11 \cdot 1$ \\
\hline w/ Spouse & $3 \cdot 7$ & $1 \cdot 8$ & $5 \cdot 7$ \\
\hline \multicolumn{4}{|c|}{ Current employment and education status } \\
\hline Student & $36 \cdot 2$ & $36 \cdot 8$ & $35 \cdot 5$ \\
\hline University & $35 \cdot 0$ & $37 \cdot 0$ & $33 \cdot 1$ \\
\hline Unemployed & $4 \cdot 9$ & $4 \cdot 8$ & $5 \cdot 0$ \\
\hline In home & $1 \cdot 4$ & $0 \cdot 1$ & $2 \cdot 5$ \\
\hline Employed & $22 \cdot 6$ & $21 \cdot 3$ & $23 \cdot 9$ \\
\hline \multicolumn{4}{|l|}{ Social class } \\
\hline I lowest & $1 \cdot 0$ & $1 \cdot 4$ & $0 \cdot 6$ \\
\hline II lower middle & $6 \cdot 8$ & $7 \cdot 4$ & $6 \cdot 1$ \\
\hline III middle & $60 \cdot 2$ & $58 \cdot 5$ & $61 \cdot 8$ \\
\hline IV upper middle & $28 \cdot 8$ & $29 \cdot 3$ & $28 \cdot 4$ \\
\hline $\mathrm{V}$ upper & $3 \cdot 2$ & $3 \cdot 4$ & $3 \cdot 1$ \\
\hline \multicolumn{4}{|l|}{ Financial situation } \\
\hline Bad, very bad & $8 \cdot 2$ & $9 \cdot 4$ & $7 \cdot 1$ \\
\hline Not good or bad & $28 \cdot 0$ & $27 \cdot 9$ & $28 \cdot 2$ \\
\hline Good & $52 \cdot 8$ & $52 \cdot 0$ & $53 \cdot 5$ \\
\hline Very good & $11 \cdot 0$ & $10 \cdot 7$ & $11 \cdot 3$ \\
\hline \multicolumn{4}{|l|}{ Urbanicity } \\
\hline Suburbs & $24 \cdot 9$ & $26 \cdot 5$ & $23 \cdot 3$ \\
\hline Urban Munich & $75 \cdot 1$ & $73 \cdot 5$ & $76 \cdot 7$ \\
\hline
\end{tabular}

the sampling frame. Table 1 presents the demographic distribution of the sample and of respondents and shows the decreasing response rates with age, the adjusted distribution of respondents that results from using weighted data, and a comparison of the weighted respondent distribution to that of Metropolitan Munich.

Table 2 shows the distribution of some sociodemographic variables in the sample. Approximately one-third is currently attending or has attended Gymnasium (secondary education between ages of 10 to 19 , which prepares students for entrance to university) and another third university. Lower school education status is reported by $11 \%$ (Grund- $/$ Hauptschule = mandatory basic school) and 18.4\% (Reaschule = an intermediate type of advanced school between Gymnasium and Hauptschule allowing 
qualification for specific university curricula). Consistent with the mandatory schooling laws, only $0.5 \%$ have dropped out of any type of these schools completely without any degree. Only $22.6 \%$ of all study participants are currently in the work force and $4.9 \%$ were registered as being unemployed. The majority of respondents are currently living with their parents, very few are currently married. The vast majority of respondents were classified into middle class, with only $7.8 \%$ belonging to the lower social classes.

\section{Diagnostic assessment}

Psychopathological and diagnostic assessments were based on the computer-assisted personal interview (CAPI) version of the Munich-Composite International Diagnostic Interview (MCIDI, Wittchen et al. $1995 a$; Wittchen \& Pfister, 1997). The M-CIDI is a modified version of the World Health Organization (WHO) CIDI, version 1.2 supplemented by questions to cover DSM-IV and ICD-10 criteria. The M-CIDI allows for the assessment of symptoms, syndromes and diagnoses of 48 mental disorders (not counting various subtypes of main disorders) along with information about onset, duration, clinical and psychosocial severity. ${ }^{1}$ Diagnostic analysis is based on the M-CIDI diagnostic package DSM-IV diagnostic algorithms (Pfister $\&$ Wittchen, 1995). Diagnostic findings reported in this paper are based on the M-CIDI/DMS-IV algorithms without using the DSM-IV hierarchy rules, unless otherwise stated in the text.

The M-CIDI includes numerous features that have been developed and tested in several methodological studies with the CIDI or modifications thereof (Wittchen, 1994; Wittchen et al. 1995b, 1996). These include: (a) the use of symptom lists and memory aids that are assembled in a separate response booklet to improve lifetime recall, ease memory search and shorten length of the interviews in the

\footnotetext{
1 A complete M-CIDI documentation including the interview and the computer programs (algorithms and CAPI version) is available, on request, in English. We do not report in this paper the prevalence rates for psychotic disorder or conduct disorder. As the reliability and validity of the standard M-CIDI diagnostic sections for these disorders were found unsatisfactory in methodological pilot work, the prevalence for these disorders will be derived from clinical consensus ratings, incorporating the more comprehensive diagnostic results from the family interviews as well as clinical re-interviews subsequent to the wave 2 interviews.
}

somatization and anxiety section; (b) symptom and criteria lists were added to help the proband answer onset and recency questions, for example, in the alcohol section to assess onset and recency of reported dependence symptoms; $(c)$ dimensional ratings were implemented in various sections for the assessment of impairment associated with core syndromes; $(d)$ key syndromes were specifically rated for their first, worst and most recent occurrence, with additional questions to allow derivation of pure crosssectional measures; (e) dimensional symptom scales such as the SCL-90-R (Derogatis et al. 1973), behavioural inhibition and premenstrual syndrome was incorporated into the interview to enable us to measure changes in key psychopathological dimension; $(f)$ separate current and lifetime ratings for the degree of impairment in various social roles (work, school, leisure time, partner, etc.) were implemented for each diagnostic section; $(g)$ more open-ended questions describing the person's problems were added, allowing the clinical editor to judge the appropriateness of the CIDI ratings; $(h)$ further, in some sections the symptom specific probe questions of the original CIDI were given up in favour of syndrome based coding; $(i)$ we also deleted many of the CIDI's skip rules in several diagnostic sections, to allow for the study of subthreshold conditions (i.e. mixed anxietydepression disorders and brief recurrent syndromes) and to improve the CIDI's ability to measure more subtle changes in diagnostic status because in adolescents we expect considerably less diagnostic stability than in adults.

The mean duration for completing the computerized (CAPI) M-CIDI, including questionnaires, was $77 \mathrm{~min}$. The decision to use the CAPI-CIDI was made after the pilot testing where CAPI interviews were shown to reduce the length of interview administration and helped to avoid interviewer coding, skip rule and probe question errors. The CAPI version of the M-CIDI was supplemented by a separate respondents' booklet that included several scales and questionnaires that are of importance for the longitudinal component of our study. In addition, there were cognitive aids to help and assist the respondent in dating symptom onset and recency and in answering complicated symptom questions and identifying course patterns. 


\section{Reliability and validity of the M-CIDI}

The psychometric properties of the M-CIDI (Wittchen et al. 1989; Wittchen, 1994) have been investigated in various sites and samples, some of which have not been published yet in English (Lachner et al. 1997; Wittchen \& Pfister, 1997). Briefly, the main findings were as follows: The test-retest reliability (TRR) of the computerized $\mathrm{M}$-CIDI has been investigated in a representative sample of community respondents aged 14 to 24 $(N=60)$. The average time interval between interviews (independent readministration by different interviewers) was 38.5 days. Reliability for lifetime DSM-IV diagnosis was high for most disorders (kappa values ranging from 0.56 (any eating disorder) to 1.0 (panic disorder) (Wittchen et al. 1997 b). The procedural validity of the M-CIDI (Wittchen et al. 1997) was investigated with three methods: $(a)$ by comparing the M-CIDI output to the Structured Clinical Interview for DSM-IV; $(b)$ by comparing the diagnostic output to the Munich Diagnostic Checklist (Hiller et al. 1994); and (c) by comparison with clinical consensus diagnoses in two samples - 104 psychiatric in- and outpatients at the Max Planck Institute of Psychiatry (aged 16 to 45 ) and 44 subjects from the community sampled as part of a pilot study (Wittchen \& Pfister, 1997). Kappa values (Yule's $Y$ if base rate was too low) taking the clinician diagnostic checklist as the gold standard were as follows (brackets indicate community sample): depressive disorder, $0.63(0.54)$, bipolar disorder, $0.72(0.51)$, panic disorder, $0.74(0.69)$, any phobia, $0.52(0.56)$, eating disorder, $0.72(0.62)$, alcohol use disorders, 0.74 (0.69), drug use disorder, $0.76(0.69)$, any somatoform disorder, $0 \cdot 49(0 \cdot 51)$.

\section{Interviewers and interviewer training}

The survey staff was highly experienced and consisted of 10 clinical interviewers and 25 fulltime professional health research interviewers. The clinical interviewers consisted of 10 clinical psychologists in postgraduate education for being licensed clinical psychologists most of whom had extensive experience in diagnostic interviewing including the CIDI and in the developmental work of the M-CIDI. The health research interviewers were recruited from Infratest-Gesundheitsforschung, a survey company specializing in health research. All interviewers underwent several screening stages and were finally chosen from a larger group of 67 applicants. They received two full weeks of training, which included the CIDI standard training components. This training period was followed by at least 10 practice interviews that were closely monitored by our staff. Immediately prior to the beginning of the study, 1 day of prefield training was done to stress important points and techniques and increase the motivation of the interviewers.

\section{Field work}

To assist interviewers in establishing contacts or with technical issues and to answer any questions from probands, a telephone hotline was installed. After contacting the probands by letter and phone, a time and location for the interview was established. Most interviews took place at the time of first contact in the home of the probands. At the beginning of the interview the written data protection explanation was given to the probands and a gift was given as an incentive for participation. The standard gift was two telephone cards each worth DM 12 (US\$8). To enhance participation, several special efforts were made during the study: (a) addresses with at least four contacts were given to another interviewer of the opposite sex and overall at least 10 attempts at contacts were given to another interviewer of the opposite sex and overall at least 10 attempts at contact (maximum 15) were realized at different times of the day and week including weekends; $(b)$ interviewers who were especially successful at contacting were trained for recontacting difficult-to-contact probands; $(c)$ motivation letters were sent to 100 unreachable probands with a telephone card enclosed and the request to call back; and $(d)$ to motivate the last indecisive probands, up to DM 60 (US\$40) was offered. The $71 \%$ response rate with a total of $N=3021$ completed interviewers was reached by the end of July 1995. In the beginning of the study the interviewers had to contact the editors after having completed three to five interviews and, throughout the field period, when handing over completed interviews. This gave interviewers an opportunity to receive help with regard to technical and content aspects of the interview. Interviewers were closely monitored throughout the field period by both 
the Infratest field staff as well as specially trained M-CIDI clinical editors. This procedure ensured that within a week of submission to the clinical editor interviews were checked according to a standard procedure for both formal consistency as well as appropriate recording techniques. During these weekly editing sessions, detailed feedback was given to every interviewer to avoid errors in later interviews. The personal feedback for interviewers was maintained throughout the study to assure a high quality of administration and to motivate the interviewers. The editors also gave instruction for reassessments of missing values or questionnaires. The correct administration of interviews was checked by random follow-up phone calls to probands.

\section{RESULTS}

\section{Lifetime and 12-month prevalence of M-CIDI/DSM-IV diagnoses}

The EDSP lifetime and 12-month prevalence estimates are reported in Table $3 \mathrm{a}$ and $\mathrm{b}$ for the total population of 14 to 24 year olds and by gender. Significant gender differences in prevalence $\left(\chi_{1}^{2}, P \leqslant 0 \cdot 05\right)$ are marked with an asterisk. Diagnostic exclusion rules were not considered except for substance abuse.

Several differences between DSM-III-R (APA, 1987), DSM-IV (APA, 1994) and the M-CIDI diagnostic algorithms should be noted because of their importance in comparing the estimates reported here with those from other studies. (1) Dependence symptoms are required in DSM-IV to have co-occurred within a 12month period. The result of this is effectively to change the qualitative threshold of accumulated symptoms necessary for a DSM-IV dependence diagnosis, thus the prevalence of dependence diagnoses is expected to be lower as compared to estimates based on DSM-III-R (Nelson, 1995; Nelson et al. 1996). (2) Depressive disorders are divided into single and recurrent subgroups, although we do not subdivide the diagnoses further into the severity subtypes in this report. (3) In an attempt to improve specificity (Wittchen et al. 1997a, Reed et al. 1997) for agoraphobia, we decided in accordance with DSM-IV to assign the diagnosis of agoraphobia only if more than one agoraphobic situation was endorsed, classifying those with fewer agoraphobic situations as Phobia/Anxiety Not Other- wise Specified (NOS). (4) Based on methodological pilot work DSM-IV criteria of significant impairment in phobias were relaxed in subjects younger than the age of 18 ; respondents meeting all phobia criteria, but not endorsing the 'significant' impairment questions were assigned a diagnosis of subthreshold phobia.

\section{Substance use disorders}

Substance disorders were the most frequent group of disorders: $26.7 \%$ of men and $8.8 \%$ of women fulfilled diagnostic criteria for either alcohol abuse or dependence on an illicit substance diagnosis at some time in their life. The 12-month rates were lower with $17 \cdot 8 \%$ and $5.7 \%$, respectively. The inclusion of nicotine dependence - a disorder that is equally prevalent in both men and women (approx. 19\%), raises these rates considerably. One-quarter of men and $7 \%$ of women reported a DSM-IV alcohol disorder, with alcohol abuse being more prevalent than alcohol dependence. Illicit substance disorders were less prevalent than alcohol use disorders with lifetime (12 month) rates of $6 \cdot 1$ $(4.3 \%)$ for men and $3.0 \%(1.4 \%)$ for women. The most frequently misused substances were cannaboids, followed by various types of stimulants (ecstasy, cocaine) and opiates. There is a relatively high intra-substance use disorder comorbidity with $29 \%$ of respondents with one substance disorder, also having at least one other substance use disorder.

\section{Mental disorders}

As shown at the bottom of Table $3 \mathrm{~b}, 27.7 \%$ of the sample fulfilled criteria for at least one DSM-IV disorder in their lifetime, $17.5 \%$ in the past 12 months. Almost a third of lifetime cases had two or more lifetime diagnoses. Also, 12 month co-morbidity was found in more than a quarter $(27 \cdot 4 \%)$ of the sample, with males having significantly more pure diagnoses than females.

Affective disorders of any type were estimated with a lifetime prevalence of $20.8 \%$ among women and $12.8 \%$ among men with single episode major depression being the most prevalent of these diagnoses (men, $7.7 \%$; women, $10.9 \%$ ). Much less prevalent were the diagnoses of dysthymia and recurrent episodes of major depression where women were 2-3 times more likely than men to have a diagnosis. Hypomanic and manic episodes as well as bipolar disorders 
Table 3a. Lifetime and 12-month prevalence of DSM-IV substance disorders $\dagger$

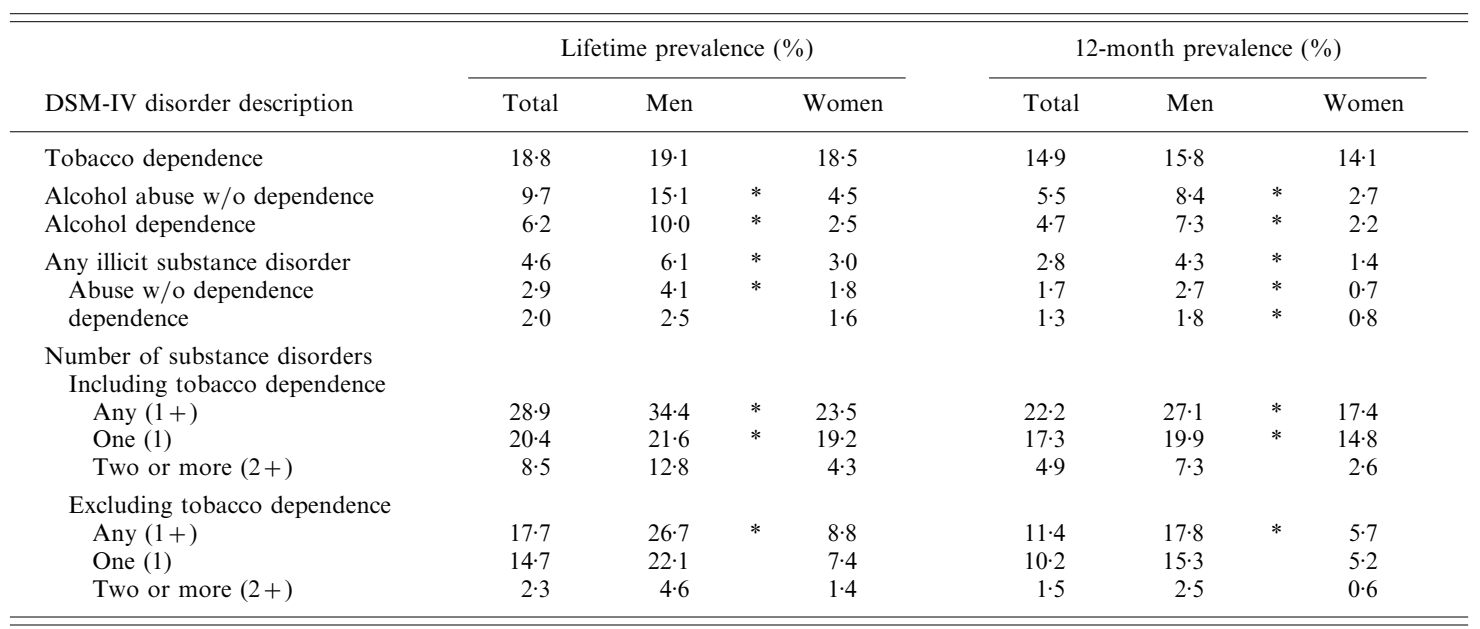

$\dagger$ A more complete table, including standard errors, is available on request.

Total $N=3021$; men, $N=1493$; women, $N=1528$.

* Indicates significant sex differences, $P<0.05$.

were relatively rare. Anxiety disorders were more than 2.5 times more prevalent among women (lifetime, $20.3 \% ; 12$ month, $13.8 \%$ ) than men (lifetime, $8.3 \%$; 12 month, $4.7 \%$ ). The most frequent types of lifetime threshold DSM-IV anxiety disorders were phobia NOS (including separation anxiety disorder), social phobia $(3.5 \%)$, agoraphobia without history of panic disorder $(2.6 \%)$ and simple phobias $(2 \cdot 3 \%)$. Infrequent lifetime diagnoses were panic disorder $(1.6 \%)$, post-traumatic stress disorder $(1.3 \%)$, generalized anxiety disorder $(0.8 \%)$ and obsessive-compulsive disorders. When interpreting the prevalence of anxiety disorders it is important to consider the following aspects: (1) panic attacks, a non-codable DSM-IV disorder, are considerably more frequent than panic disorder; $5.7 \%$ of women and $2.9 \%$ of men had experienced at least one DSM-IV panic attack; (2) the M-CIDI algorithms for agoraphobia excludes respondents that relate their symptomatology to only one out of the five prototypical agoraphobic situations and classifies them under phobia NOS, a category where we also group cases with separation anxiety disorders; (3) subthreshold anxiety disorders, defined as cases fulfilling all DSM-IV diagnostic criteria except for the impairment criteria, were considerably more frequent than threshold diagnoses-lifetime prevalence for subthreshold social phobia was twice as high and for simple phobia seven times higher than for threshold disorders.

Eating disorders had an overall prevalence of $3.0 \%$ and were considerably more frequent among women $(4 \cdot 9 \%)$ than men $(1 \cdot 1 \%)$. Fullblown DSM-IV anorexia nervosa and bulimia were found, with three exceptions, only in females. Atypical eating disorders (defined as falling short by just one DSM-IV criterion) were slightly more frequent than threshold disorders in females and dominant in males. Specific threshold somatoform disorders were absent in our sample except for persistent pain disorder (lifetime, $1.2 \% ; 12$ month, $0.7 \%$ ). However, subthreshold somatoform syndromes (conversion, somatization and undifferentiated syndromes) leading to repeated medical helpseeking were relatively frequent manifestations occurring in $7 \cdot 1 \%$ of men and $14.9 \%$ of women.

To summarize, taking substance and other mental disorders together, males $(38.3 \%)$ were affected as frequently as females $(39 \cdot 4 \%)$ by at least one lifetime disorder. Interestingly, for both lifetime and 12-month disorders there were no overall gender differences in the probability of having any disorder or of being comorbid. However, men are more likely than women to meet criteria for any substance disorder while women are more likely than men 
Table 3b. Lifetime and 12-month prevalence of DSM-IV non-substance disorders $\dagger$

\begin{tabular}{|c|c|c|c|c|c|c|c|c|}
\hline \multirow[b]{2}{*}{ DSM-IV disorder description } & \multicolumn{4}{|c|}{ Lifetime prevalence $(\%)$} & \multicolumn{4}{|c|}{ 12-month prevalence $(\%)$} \\
\hline & Total & Men & & Women & Total & Men & & Women \\
\hline Any affective disorder & $16 \cdot 8$ & $12 \cdot 8$ & $*$ & $20 \cdot 8$ & $10 \cdot 1$ & $6 \cdot 4$ & $*$ & $13 \cdot 8$ \\
\hline Hypomania & 1.5 & $1 \cdot 4$ & & 1.7 & $1 \cdot 2$ & $0 \cdot 9$ & & 1.5 \\
\hline Single episode mania & $0 \cdot 1$ & $0 \cdot 0$ & & $0 \cdot 1$ & $0 \cdot 1$ & $0 \cdot 0$ & & $0 \cdot 1$ \\
\hline Bipolar I & $1 \cdot 4$ & $1 \cdot 1$ & & 1.7 & $1 \cdot 3$ & $0 \cdot 9$ & $*$ & 1.6 \\
\hline Bipolar II & $0 \cdot 4$ & $0 \cdot 2$ & $*$ & $0 \cdot 7$ & $0 \cdot 4$ & $0 \cdot 1$ & $*$ & $0 \cdot 7$ \\
\hline Single episode of depression & $9 \cdot 3$ & $7 \cdot 7$ & $*$ & $10 \cdot 9$ & $3 \cdot 6$ & $2 \cdot 4$ & $*$ & $4 \cdot 7$ \\
\hline Recurrent depression & $2 \cdot 5$ & $1 \cdot 4$ & $*$ & $3 \cdot 6$ & 1.7 & $0 \cdot 9$ & $*$ & $2 \cdot 5$ \\
\hline Dysthymia & $3 \cdot 0$ & $1 \cdot 5$ & $*$ & $4 \cdot 5$ & $2 \cdot 9$ & $1 \cdot 4$ & $*$ & $4 \cdot 4$ \\
\hline Any anxiety disorder ${ }^{1}$ & $14 \cdot 4$ & $8 \cdot 3$ & $*$ & $20 \cdot 3$ & $9 \cdot 3$ & $4 \cdot 7$ & $*$ & $13 \cdot 8$ \\
\hline Including subthreshold ${ }^{1,2}$ & $26 \cdot 7$ & $19 \cdot 3$ & $*$ & $34 \cdot 0$ & $18 \cdot 1$ & $11 \cdot 4$ & $*$ & $24 \cdot 5$ \\
\hline Panic attack & $4 \cdot 3$ & $2 \cdot 9$ & $*$ & $5 \cdot 7$ & $2 \cdot 7$ & $1 \cdot 2$ & $*$ & $4 \cdot 2$ \\
\hline Panic diagnosis $\mathrm{w} /, \mathrm{w} / \mathrm{o}$ agoraphobia & $1 \cdot 6$ & $0 \cdot 8$ & $*$ & $2 \cdot 4$ & $1 \cdot 2$ & $0 \cdot 4$ & $*$ & $2 \cdot 0$ \\
\hline Agoraphobia w/o panic diagnosis & $2 \cdot 6$ & $1 \cdot 0$ & $*$ & $4 \cdot 2$ & 1.6 & $0 \cdot 6$ & $*$ & $2 \cdot 6$ \\
\hline Phobia NOS & $5 \cdot 2$ & $3 \cdot 3$ & $*$ & $7 \cdot 0$ & $2 \cdot 7$ & $1 \cdot 2$ & * & $4 \cdot 1$ \\
\hline Social phobia & $3 \cdot 5$ & $2 \cdot 2$ & $*$ & $4 \cdot 8$ & $2 \cdot 6$ & 1.5 & * & $3 \cdot 7$ \\
\hline Including subthreshold ${ }^{2}$ & $7 \cdot 3$ & $4 \cdot 9$ & $*$ & $9 \cdot 5$ & $5 \cdot 2$ & $3 \cdot 2$ & $*$ & $7 \cdot 2$ \\
\hline Simple phobia & $2 \cdot 3$ & $1 \cdot 2$ & $*$ & $3 \cdot 3$ & $1 \cdot 8$ & $1 \cdot 0$ & $*$ & $2 \cdot 6$ \\
\hline Including subthreshold ${ }^{2}$ & $16 \cdot 0$ & $12 \cdot 5$ & $*$ & $19 \cdot 5$ & $10 \cdot 7$ & $7 \cdot 2$ & $*$ & $14 \cdot 1$ \\
\hline Generalized anxiety & $0 \cdot 8$ & $0 \cdot 8$ & & $0 \cdot 8$ & $0 \cdot 5$ & $0 \cdot 5$ & & $0 \cdot 6$ \\
\hline Obsessive-compulsive & $0 \cdot 7$ & $0 \cdot 5$ & & $0 \cdot 9$ & 0.6 & $0 \cdot 4$ & & $0 \cdot 8$ \\
\hline Post-traumatic stress & $1 \cdot 3$ & $0 \cdot 4$ & $*$ & $2 \cdot 3$ & $0 \cdot 7$ & $0 \cdot 1$ & $*$ & $1 \cdot 3$ \\
\hline Any eating disorder & $3 \cdot 0$ & $1 \cdot 1$ & $*$ & $4 \cdot 9$ & $1 \cdot 5$ & $0 \cdot 7$ & $*$ & $2 \cdot 3$ \\
\hline Anorexia nervosa & 0.6 & $0 \cdot 1$ & $*$ & $1 \cdot 0$ & $0 \cdot 1$ & $0 \cdot 0$ & $*$ & $0 \cdot 3$ \\
\hline Atypical anorexia nervosa & 0.8 & $0 \cdot 4$ & $*$ & $1 \cdot 3$ & 0.5 & $0 \cdot 3$ & $*$ & $0 \cdot 6$ \\
\hline Bulimia nervosa & $0 \cdot 9$ & $0 \cdot 0$ & & 1.7 & $0 \cdot 3$ & $0 \cdot 0$ & & $0 \cdot 7$ \\
\hline Atypical bulimia nervosa & $1 \cdot 1$ & $0 \cdot 6$ & $*$ & $1 \cdot 5$ & $0 \cdot 6$ & $0 \cdot 4$ & $*$ & $0 \cdot 8$ \\
\hline Any somatoform disorder ${ }^{3}$ & $1 \cdot 2$ & $0 \cdot 2$ & $*$ & $2 \cdot 3$ & $0 \cdot 7$ & $0 \cdot 1$ & $*$ & $1 \cdot 3$ \\
\hline Somatization & $0 \cdot 0$ & $0 \cdot 0$ & & $0 \cdot 0$ & $0 \cdot 0$ & $0 \cdot 0$ & & $0 \cdot 0$ \\
\hline Subthreshold somatoform disorders ${ }^{4}$ & $11 \cdot 0$ & $7 \cdot 1$ & $*$ & $14 \cdot 9$ & $6 \cdot 6$ & $3 \cdot 9$ & $*$ & $9 \cdot 1$ \\
\hline Hypochondriasis & $0 \cdot 0$ & $0 \cdot 0$ & & $0 \cdot 1$ & $0 \cdot 0$ & $0 \cdot 0$ & & $0 \cdot 1$ \\
\hline Persistent Pain & $1 \cdot 2$ & $0 \cdot 2$ & $*$ & $2 \cdot 3$ & $0 \cdot 7$ & $0 \cdot 1$ & $*$ & $1 \cdot 3$ \\
\hline \multicolumn{9}{|l|}{ Number of threshold disorders ${ }^{1,3}$} \\
\hline Any $(1+)$ & $27 \cdot 7$ & $19 \cdot 4$ & $*$ & $35 \cdot 7$ & $17 \cdot 5$ & $10 \cdot 3$ & $*$ & $24 \cdot 5$ \\
\hline One (1) & $19 \cdot 3$ & $15 \cdot 4$ & $*$ & $23 \cdot 1$ & $12 \cdot 7$ & $8 \cdot 1$ & $*$ & $17 \cdot 2$ \\
\hline Two or more $(2+)$ & $8 \cdot 3$ & $4 \cdot 0$ & & $12 \cdot 6$ & $4 \cdot 8$ & $2 \cdot 2$ & & $7 \cdot 4$ \\
\hline
\end{tabular}

$\dagger$ A more complete table, including standard errors, is available on request.

Total, $N=3021$; men, $N=1493$; women, $N=1528$.

* Indicates significant sex differences, $P<0.05$.

1 Not including panic attack.

2 Including subthreshold and threshold diagnoses.

3 Not including undifferentiated somatization.

4 Undifferentiated somatization is currently being assessed for reliability and validity.

to meet criteria for affective, anxiety, somatoform and eating disorders. Evaluation of diagnosis counts among the substance and nonsubstance disorders indicates that men are more likely to meet criteria for a substance disorder $\left(\chi_{1}^{2}, P<0.05\right)$ and, among respondents with any substance disorder, men are more likely to meet criteria for more than one $\left(\chi_{1}^{2}, P<0 \cdot 05\right)$, while women are more likely to meet criteria for a non-substance disorder $\left(\chi_{1}^{2}, P<0 \cdot 05\right)$ and, likewise, among respondents with any non-substance disorder women are more likely than men to be co-morbid $\left(\chi_{1}^{2}, P<0.05\right)$.

\section{Socio-demographic correlates of disorder}

Although lifetime as well as 12-month associations are reported, we present only the lifetime findings in detail (Table 4) because there were no remarkable differences besides the strength of association being slightly higher with lifetime diagnoses. For all disorders higher age groups have significantly higher odds with the highest odds for alcohol use disorders in the age group 21 to 24. Consistent with other studies we also find that women have higher prevalence of affective $(\mathrm{OR}=1 \cdot 8)$, anxiety $(2 \cdot 7)$, eating (4.6) 


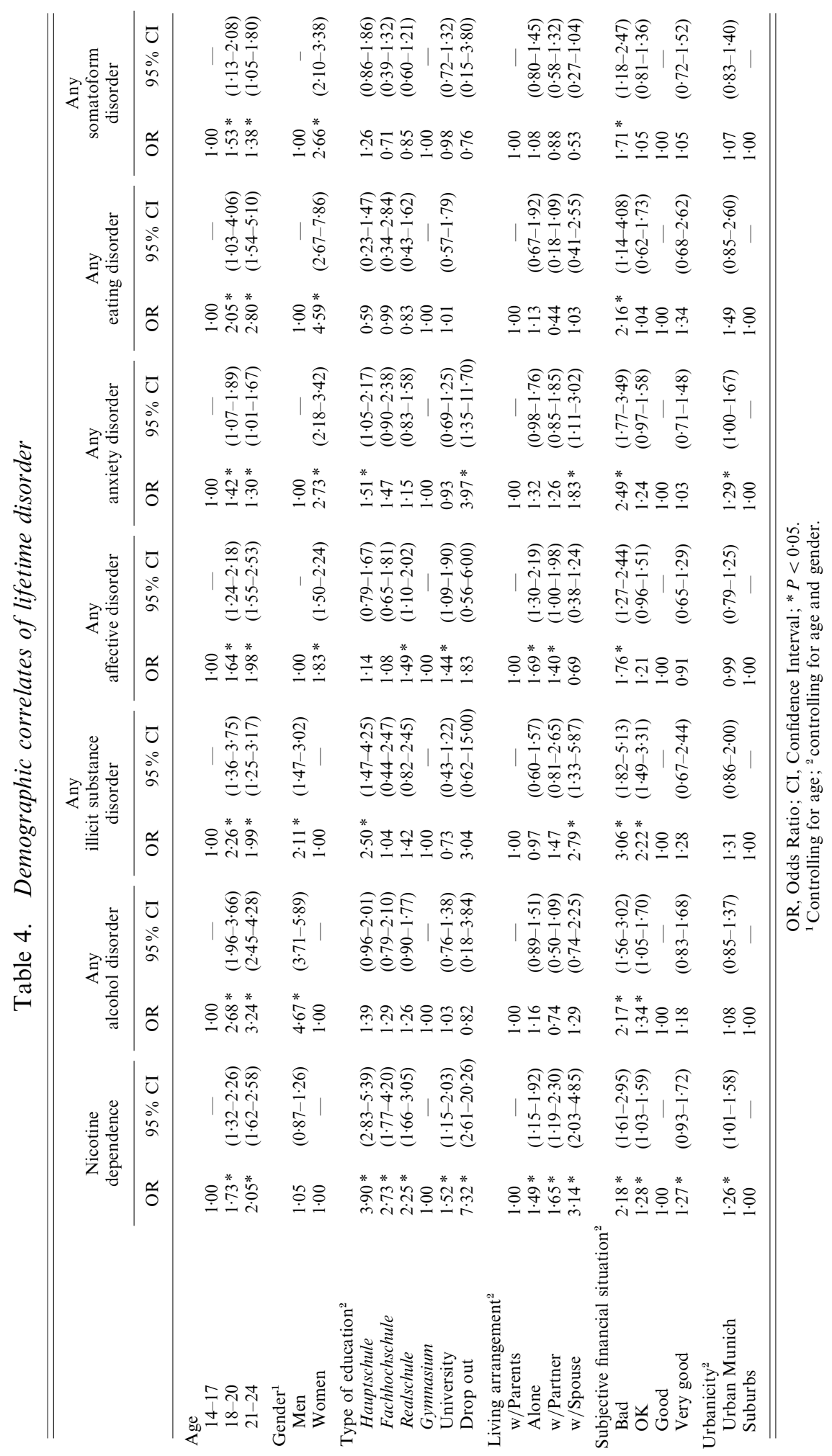


Table 5. Self-rated degree of impairment at worst episode and in the past month

\begin{tabular}{|c|c|c|c|c|c|c|c|}
\hline \multirow[b]{3}{*}{ DSM-IV disorder description } & & & & \multicolumn{4}{|c|}{ Past month (\%) } \\
\hline & \multicolumn{3}{|c|}{ Worst episode $(\%)$} & \multirow[b]{2}{*}{$(N)$} & \multirow{2}{*}{$\begin{array}{c}\begin{array}{l}\text { Work/School/ } \\
\text { Home }\end{array} \\
\text { Very much }\end{array}$} & \multirow{2}{*}{$\frac{\text { Leisure }}{\text { Very much }}$} & \multirow{2}{*}{$\begin{array}{c}\begin{array}{c}\text { Social } \\
\text { contacts }\end{array} \\
\text { Very much }\end{array}$} \\
\hline & $(N)$ & Some & Very much & & & & \\
\hline Hypomania & (46) & 42 & 39 & & - & - & - \\
\hline Single episode mania & (2) & 0 & 79 & & - & - & - \\
\hline Any bipolar & (54) & 6 & 94 & (29) & 21 & 22 & 20 \\
\hline Single episode of depression & (280) & 13 & 86 & (27) & 24 & 14 & 22 \\
\hline Recurrent depression & (76) & 10 & 90 & (11) & 42 & 50 & 46 \\
\hline Dysthymia & (91) & 17 & 67 & & - & - & - \\
\hline Panic disorder w/ agoraphobia & (25) & 26 & 71 & (6) & 38 & 19 & 19 \\
\hline Panic disorder w/o agoraphobia & (24) & 35 & 35 & (8) & 18 & 25 & 13 \\
\hline Agoraphobia w/o panic disorder & (79) & 39 & 27 & (24) & 9 & 7 & 16 \\
\hline Phobia NOS & (157) & 37 & 15 & (49) & 1 & 3 & 0 \\
\hline Social phobia & (106) & 34 & 58 & (35) & 24 & 26 & 25 \\
\hline only subthreshold & (114) & 51 & 0 & (37) & 10 & 0 & 0 \\
\hline Simple phobia & (69) & 0 & 100 & (23) & 13 & 32 & 9 \\
\hline only subthreshold & (416) & 37 & 3 & (105) & 1 & 4 & 0 \\
\hline Generalized anxiety & (24) & 13 & 87 & (7) & 46 & 61 & 84 \\
\hline Obsessive-compulsive & (22) & 32 & 53 & (12) & 48 & 46 & 31 \\
\hline Post-traumatic stress & (40) & 28 & 70 & & - & - & - \\
\hline Persistent pain & (37) & 66 & 34 & (13) & 55 & 55 & 12 \\
\hline
\end{tabular}

- Indicates that past month impairment was not assessed.

and somatoform conditions (2.7), except for alcohol and illicit substance use disorders, where males had a $4 \cdot 7$ (illicit) and $2 \cdot 1$-fold increased risk. No significant differences were found for nicotine dependence. For type of education our study does not reveal strong consistent relationships across disorders as found in USAmerican studies (Kessler et al. 1994). Lower educational status (Hauptsschule) was significantly related only to illicit substance use (OR, $2.5)$ as well as moderately to anxiety disorders $(\mathrm{OR}, 1 \cdot 5)$. It is noteworthy that dropping out of school was strongly related to nicotine dependence (7.3) and anxiety disorders; whereas the association for illicit substance disorders failed to reach statistical significance. Consistent with most other studies we find that lower income and lower subjective socioeconomic status is significantly related to all disorders with ORs ranging from 1.7 for somatoform disorders to a high of $3 \cdot 1$ for illicit substance use disorders. Urbanicity was not associated with mental disorders, except for a slightly elevated odds for anxiety disorders. Although we controlled for age and gender, living with parents was found to be associated with a lower risk of any disorder. Living alone was associated with slightly higher odds of nicotine dependence and mood disorder, living with a partner increased the odds for nicotine dependence and mood disorder and living with a spouse was associated with nicotine dependence, illicit substance disorder and anxiety disorders.

\section{Disorder-specific disabilities and impairments}

Because of an interest in episode-associated impairment, the M-CIDI included a general assessment of impairment during the worst episode of symptomatology and a more specific assessment of economic, social, and leisure impairment during the 4 weeks before interview. In addition, the number of days in the past month during which a respondent was unable to complete work, school or household responsibilities ('days lost') as a result of disorder was assessed. Results of this assessment are shown in Tables 5 and 6 .

\section{Self-reported disabilities during the worst episode}

Threshold simple phobia, depressive, manic and bipolar disorders, followed by GAD and panic disorder with agoraphobia were associated most frequently with severe psychosocial disabilities during the lifetime peak of the episode. Sub- 
Table 6. Current disorders: percentage of days lost and median days missed

\begin{tabular}{|c|c|c|c|c|c|}
\hline & \multirow{2}{*}{$\begin{array}{l}\% \mathrm{w} / \text { days } \\
\text { lost due } \\
\text { to disorder }\end{array}$} & & \multicolumn{2}{|c|}{$\begin{array}{l}\text { Among those } \\
\text { missing any days }\end{array}$} & \\
\hline & & & Median & Mode & \\
\hline \multicolumn{6}{|c|}{ Any 1 month mental disorder } \\
\hline One (1) & $34 \cdot 6$ & & 4 & 2 & \\
\hline Two or more $(2+)$ & $60 \cdot 5$ & $*$ & 8 & 4 & * \\
\hline \multicolumn{6}{|c|}{ Any 1 month substance disorder $\dagger$} \\
\hline One (1) & $26 \cdot 7$ & & 3 & 1 & \\
\hline Two or more $(2+)$ & $15 \cdot 7$ & * & 4 & 3 & \\
\hline
\end{tabular}

* Indicates significant differences between 1-month co-morbid and 1 -month non-co-morbid respondents, $P<0.05$.

$\dagger$ Excluding tobacco dependence.

threshold phobias, persistent pain, agoraphobia without panic and hypomanic episodes were found to be least impairing, with social phobia and obsessive-compulsive disorder in the middle.

\section{Current disabilities}

With regard to disease-specific social domainimpairments and disabilities of current cases during the past month a slightly different picture emerges: recurrent depressive disorders, generalized anxiety and obsessive-compulsive disorders were the most impairing with regard to work, school and household management, leisure activities and social contacts. Subthreshold phobias, Phobia NOS and agoraphobia without panic were determined as the least severe in all three areas evaluated. But there are also some remarkable differences in disability patterns for anxiety disorders: (1) panic disorder with agoraphobia seems to be predominantly related to impairments and disabilities in work, education and household management; (2) threshold simple phobia effects leisure time activities more frequently; (3) persistent pain disorders have a strong affect on work and leisure time activities, but less frequently on social contacts; whereas (4) generalized anxiety affects social contacts most frequently.

\section{Days lost in work productivity}

The substantial burden associated with mental and substance disorders even in adolescents and young adults is shown in Table 6 . Upon being asked on how many days in the past month the
Table 7. Professional help-seeking among respondents with a lifetime disorder

\begin{tabular}{|c|c|c|c|c|}
\hline & $(N)$ & $\begin{array}{c}\text { Any } \\
\%\end{array}$ & $\begin{array}{c}\text { Physician } \\
\%\end{array}$ & $\begin{array}{c}\text { Other } \\
\text { professional } \\
\%\end{array}$ \\
\hline Hypomania & $(46)$ & 0 & 0 & 0 \\
\hline Single episode mania & (2) & 0 & 0 & 0 \\
\hline Any bipolar & (54) & 35 & 22 & 13 \\
\hline Single episode of depression & $(280)$ & 24 & 19 & 4 \\
\hline Recurrent depression & (76) & 40 & 20 & 20 \\
\hline Dysthymia & (91) & 46 & 30 & 16 \\
\hline $\begin{array}{l}\text { Panic disorder w/ } \\
\text { agoraphobia }\end{array}$ & $(25)$ & 81 & 64 & 18 \\
\hline $\begin{array}{l}\text { Panic disorder w/o } \\
\text { agoraphobia }\end{array}$ & $(24)$ & 50 & 37 & 13 \\
\hline $\begin{array}{l}\text { Agoraphobia w/o } \\
\text { panic disorder* }\end{array}$ & (16) & 13 & 13 & 0 \\
\hline Phobia NOS* & (49) & 5 & 5 & 0 \\
\hline Social phobia & (106) & 43 & 25 & 18 \\
\hline only subthreshold & (114) & 0 & 0 & 0 \\
\hline Simple phobia $\dagger$ & (69) & - & - & - \\
\hline Generalized anxiety & (24) & 58 & 58 & 0 \\
\hline Obsessive-compulsive & $(22)$ & 41 & 31 & 10 \\
\hline Post-traumatic stress & (40) & 63 & 44 & 18 \\
\hline Eating & $(91)$ & 24 & 24 & 0 \\
\hline
\end{tabular}

* Only assessed for the past 4 weeks.

$\dagger$ Not assessed.

subject had been completely unable to work, go to school or manage the household, $34.6 \%$ of subjects with just one diagnosis of a mental disorder and $60.5 \%$ of those with co-morbidity (two or more disorders) reported having missed at least 1 day of work because of their psychological problems. The median (mode) number of days missed also doubled from 4 (2) to 8 (4) among those with more than one mental disorder. Impairment associated with substance disorders was less frequent.

\section{Professional helpseeking}

Table 7 displays considerable disorder-specific treatment rates for respondents with a lifetime disorder. Almost $50 \%$ of all lifetime cases indicated having contacted at least once either a medical doctor (e.g. family doctors, internists, psychiatrists), or other health professionals predominantly ( $94 \%$ psychologists in various settings, e.g. counselling centres, office-based), because of their disorder. Panic disorder, PTSD and GAD are the three conditions with highest professional help-seeking rates (over $50 \%$ of those affected), followed by dysthymia (46\%), recurrent depressions $(40 \%)$, social phobia $(43 \%)$ and OCD (41\%). For depressive 
disorders, it is noteworthy that $9.5 \%$ of all depressive cases had received in-patient treatment at least once in their life. Lowest helpseeking rates were found for phobias and eating disorders. Disorders with relatively high psychologist help-seeking rates are: recurrent depressive disorder, PTSD, social phobia, and panic with agoraphobia.

\section{DISCUSSION}

This paper is the first of a series of reports from this ongoing longitudinal study about early developmental conditions of mental disorders, highlighting predominantly the frequency and the extent of problems associated with mental disorders in adolescence and young adulthood. Subsequent publications will examine age and mode of onset as well as the developmental patterns of disorders including co-morbidity. Before discussing our findings, some limitations and caveats should be mentioned. (1) This is to our knowledge the first epidemiological study using diagnostic definitions and criteria of DSMIV (APA, 1994). Thus, direct and detailed comparisons with other adolescent and adult community surveys, such as the National Comorbidity Survey (NCS, Kessler et al. 1994) should be cautioned, because of DSM-IV's more or less subtle changes in diagnostic criteria and threshold definitions that have been a basis of the present study. (2) With regard to comparisons with the existing child psychiatric studies, direct comparisons are even further complicated by considerable additional differences in sampling, case finding methods and diagnostic categories (Fleming \& Offord, 1990). Here one needs to take into account: (a) that we use a broader diagnostic spectrum than most previous child and adolescent surveys; and (b) that we do not report specific child psychiatric diagnosis (conduct disorder, separation anxiety disorder, attention-deficit disorder, etc.), that will be published in a separate paper, including the findings of parents interviews. A key characteristic of our study is that we relied exclusively on diagnostic information provided by the adolescents and young adults and did not include parents reports. We were encouraged to do so by our findings that the M-CIDI diagnoses dealt with in the present paper are as reliable and valid in respondents aged 14 to 24 years as in older respondents (Wittchen \& Pfister, 1997). We also felt justified in this methodological choice because the findings demonstrated that the reliability of child reports increase by age, whereas the reliability of parents' report decrease sharply (Edelbrock et al. 1985). Furthermore, we consider the benefits of using the same diagnostic instrument consistently throughout all waves of our longitudinal study to be greater than introducing variance by using different diagnostic assessment methods. However, we also acknowledge that psychotic-, conduct- and other childhood disorders do require a more complex diagnostic approach, including reports of significant others together with best-estimateconsensus-diagnoses. Referring to preliminary analyses, it might be of interest to mention that it seems to be unlikely that the inclusion of these additional diagnoses will dramatically change the overall prevalence rate for mental disorders although we expect these data will strongly modify our co-morbidity findings. The EDSP study was conducted in a circumscribed geographical area (metropolitan Munich, Germany). Although it is likely that our prevalence and impairment findings can be generalized to other metropolitan areas, it is less likely to be so for variables, such as our treatment and professional help-seeking findings, given the considerable differences in mental health service delivery in our country (free and basically unrestricted access to mental health services).

\section{Frequency of mental disorders and co-morbidity}

Using strict DSM-IV criteria our study estimates that slightly less than one-fifth $(17 \cdot 7 \%)$ of our sample aged 14 to 24 has been affected by at least one threshold substance use disorder in their lifetime and more than a quarter $(27.6 \%)$ met criteria for a mental disorder. Overall, $39 \%$ of this young population met criteria for a substance or mental disorder. The current (12 month) prevalence estimates are only slightly lower with $11.4 \%$ for substance use disorders and $17.5 \%$ for mental disorders, underlining the considerable persistence of these conditions in this age group. In light of the above mentioned methodological restrictions for direct comparisons between studies, there is nevertheless remarkable consistency in prevalence across studies. Our overall estimate of $39 \%$ is quite similar to the NCS, where $48 \%$ of a US national 
sample ( 15 to 54 years of age) met criteria for a lifetime disorder (Kessler et al. 1994), the $42 \%$ in the Dunedin birth cohort study (McGee et al. 1992). Lewinsohn et al.'s (1993, 1994, 1995), lifetime rate of $42.8 \%$ in high school students as well as Cuffe et al.'s (1995) lifetime rate of $20 \%$ (this study did not report substance use prevalence) in six public middle and high school attenders. However, although the overall proportion of adolescents affected by at least one mental or substance disorder looks similar across studies, the diagnostic composition is quite different. The above mentioned child and adolescent studies report fairly consistently considerably lower substance use disorder prevalence, whereas we are quite consistent with the NCS (Kessler et al. 1994) in that substance use disorders are the most frequent lifetime and 12 -month diagnoses in young males followed by depressive and anxiety disorders. For young women, the rank order is depressive followed by anxiety disorders, whereas substance use disorders are considerably less frequent in females. Irrespective of the large gender-specific difference in substance disorder prevalence, the likelihood of men and women being affected in their lifetime (men, $34 \% v$. females, $33 \%$ ) as well as during the past 12 months by at least one mental disorder is almost equal in our study, because of females' higher rates for anxiety, depressive, eating and somatoform disorders.

\section{Affective disorders}

For affective disorders, compared with the NCSDSM-III-R rates we found almost identical estimates for single and recurrent depression (EDSP, $11 \cdot 8 v$. NCS, $12.7 \%$, Kessler et al. 1994) in this age group; in comparison to other adolescent studies (Bird et al. 1988; Garrison et al. 1992; Lewinsohn et al. 1993, 1994, 1995; Feehan et al. 1997) our findings are within the range of previous lifetime estimates (2.3 to $25 \cdot 3 \%$ ). Relative good agreement across studies also exists with regard to bipolar disorder (range: 0.6 to $1.4 \%$ ) and dysthymia ( 3.0 to $3.6 \%$ ).

\section{Alcohol use disorders}

In accordance with several US-American studies (Robins \& Regier 1991; Lewinsohn et al. 1993, 1994, 1995; Kessler et al. 1994; Nelson 1995) we also find that alcohol use disorders, specifically abuse are among the most frequent forms of specific mental disorders in 14 to 24 year old subjects. It is noteworthy, that this finding is in contrast to considerably lower estimates, obtained in several German community studies (review: Perkonigg et al. 1996) that have used clinical case-finding methods for alcohol dependence and abuse.

\section{Illicit drug use}

Illicit drug use disorders in the EDSP were determined with a lifetime prevalence of $4 \cdot 6 \%$, a considerable increase from the low $2 \%$ determined in previous national surveys of the last decade (such as the Munich Follow-up Study, Wittchen et al. 1987; Perkonigg et al. 1996). Nevertheless, our rates are still considerably lower than those found in the US. Evidence from various sources (European Monitoring Center for Drugs and Drug Addition, 1996) support that both availability, as well as consumption rates, of illegal drugs are still noticeably lower in Germany than the US. Thus, it seems quite plausible that our lower EDSP rates (illicit drug dependence EDSP, $2 \cdot 5$ v. $7 \cdot 2 \%$ in the NCS and abuse 2.5 v. $5.4 \%$ ) reflect a true difference, since it is unlikely that revised criteria of DSM-IV would account for such a large difference.

\section{Anxiety disorders}

Whereas the lifetime DSM-IV rates for generalized anxiety disorder $(0.8 \%)$, obsessivecompulsive disorder $(0.7)$ and panic disorder (1.6) do not indicate major differences in comparison with previous studies, our prevalence estimates for post-traumatic stress disorder (PTSD) and phobias are considerably lower and require further exploration. As compared to several more recent US-American studies (12.3\% Resnick et al. 1993; 7.8\% Kessler et al. 1995) - even when the relatively young age of our sample is taken into account-our PTSD prevalence of $1.3 \%$ is considerably lower. More detailed examinations for potential reasons of this difference (Perkonigg \& Wittchen, 1997) suggest, that subjects in our sample experience traumatic events less frequently than their American counterparts. For simple and social phobia the literature indicates tremendous variation in findings. Our EDSP rates of a low 2.3\% for threshold DSM-IV simple phobias and for threshold social phobia, resemble more fairly 
low estimates from recent child and adolescent surveys (Bird et al. 1988; Lewinsohn et al. 1993; Milne et al. 1995; range, 2.3-3.9\%). But they are in contrast with the ECA concerning simple/ specific phobias (Robins \& Regier, 1991) and with the NCS for both conditions. The latter study reported using an almost identical assessment strategy, a lifetime rate of $10.8 \%$ for simple and $14.9 \%$ for social phobia (Magee et al. 1996). Closer examination of this difference suggests that the lower EDSP prevalence is mainly due to stricter questions for the DSM severity and impairment criterion for phobias. Whereas the M-CIDI DSM-IV algorithm requires stringently, marked distress or significant psychosocial interference in at least one social role area (did your anxiety or the avoidance interfere a lot with ...?), the DSM-III-R algorithms incorporated two additional 'softer' questions to qualify for the impairment criterion. Relaxing our DSM-IV criterion in a similar way, raises the prevalence to a high of $16 \%$ for subthreshold simple and $7.3 \%$ for subthreshold social phobia. Further investigations are necessary to clarify which way is the most valid. Because we feel that our subthreshold cases constitute an important clinically relevant subgroup of phobias, we will now examine, in the subsequent waves of our study, to what degree subthreshold anxiety disorders might be a prodromal stage of more severe mental disorders. The comparatively low agoraphobia rate of $2.6 \%$ lifetime is the result of the stricter M-CIDI/DSM-IV diagnostic algorithms, that assigns a phobia NOS diagnoses to respondents, who endorse only one of the protypical agoraphobic situations, assessed with the M-CIDI. A recent study by Reed et al. (1997) has shown, that the number of false positive diagnoses - as compared to clinical diagnoses - is drastically reduced, by this algorithm, that matches closely DSM-IV recommendations in the phobia chapter (APA, 1994, p. 406).

\section{Eating disorders}

These were estimated with a fairly high lifetime prevalence of $4.9 \%$ for women, the majority of which having DSM-IV bulimia $(1.7 \%)$ or subthreshold bulimia (1.5\%). Unexpectedly, we also found a high of $1 \cdot 1 \%$ of young males with both atypical bulimia as well as anorexia. Fullblown threshold anorexia nervosa and bulimia however were found, with three exceptions, only in females. Atypical eating disorders (defined as falling short by just one DSM-IV criterion, mostly due to the endocrine change criterion) were slightly more frequent than threshold disorders in females and dominant in males.

\section{Somatoform syndromes and disorders}

As a prospective study special attention was paid to the evaluation of various somatoform syndromes and disorders, that are believed to occur early in life (DSM-IV, APA 1994) and might be important precursor conditions for other disorders. Not completely unexpected specific threshold somatoform disorders (somatization, pain disorder, conversion disorder and hypochondriasis) were almost absent in this young sample, except for persistent pain disorder (lifetime $1 \cdot 2 \% ; 12$-month, $0 \cdot 7 \%$ ). However, subthreshold syndromes, most frequently conversion somatization, subthreshold somatization disorder and other undifferentiated somatoform syndromes were relatively frequent manifestations occurring in $7 \cdot 1 \%$ of men and $14.9 \%$ of women. All subthreshold cases revealed repeated professional help-seeking, impairment and suffering over a period of at least 6 months, thus we have only few doubts that this group is of clinical and epidemiological relevance.

\section{Co-morbidity}

Even with the relatively young age of our sample, we also find substantial lifetime and 12month co-morbidity rates. Lifetime, $35 \%$ of all respondents with any diagnosis have at least one additional diagnosis (not taking into account tobacco dependence and within-illicit drug disorder co-morbidity). Even when focusing on the past 12 months one-third of cases are co-morbid, only $66 \%$ of cases have pure disorders. Our comorbidity figures are only slightly lower than those found in the NCS (Kessler et al. 1994) and almost identical to those found in previous adolescent studies (Lewinsohn et al. 1993, 1994, 1995; Cuffe et al. 1995). These findings confirm that mental and substance use disorders - in this study defined by DSM-IV criteria - are prevalent in adolescence and young adults, and even in young age groups co-morbidity is a frequent phenomenon. 


\section{Socio-demographic correlates}

The associations with sociodemographic factors examined generally confirm that most risk factors identified in population surveys of adults (sex, age, socio-economic status, living arrangement) also apply to adolescents and young adults. Higher age groups were found to have significantly higher odds to have a disorder, women have significantly higher odds of affective, anxiety, eating and somatoform conditions, while males had a $2 \cdot 1$ higher risk for licit substance and a 4.7 higher risk for illicit substance disorders. Lower socio-economic status (social class and income) was also significantly related with an increased prevalence of almost all disorders, with highest odds for illicit drug use. However, we did not find in our sample strong and consistent relationship across disorders (Kessler et al. 1994), lower educational status was significantly related only to two disorders, illicit substance disorders as well as moderately to anxiety disorders. The risk factor 'dropping out of school' - a strong risk factor in US studies - is hard to investigate in our study; because respondents dropping out of school or not finishing the mandatory minimum 10 years of schooling and professional training schools are rare in Germany.

\section{Disability and help-seeking}

Based on detailed assessments of lifetime and cross-sectional disabilities and impairments, we could show that mental disorders in adolescence are associated with fairly disorder-specific problems in social role functioning. The most impairing lifetime 'at the peak of the worst episode' disorders were affective disorders, generalized anxiety disorder as well as panic with agoraphobia and-quite unexpectedthreshold simple phobias, whereas phobias NOS (including separation anxiety disorder), subthreshold phobias as well as 'pure' substance use disorders are the least impairing in adolescence and young adulthood. In terms of the current (4 weeks preceding the interview) social domain-specific (work and education, leisure, social contacts) disabilities examined, recurrent depression, GAD and OCD, were the three disorders displaying most frequently and uniformly disabilities and impairments in all areas. Persistent pain, panic, agoraphobia as well as simple phobia were rarely associated with current social contact impairments, but indicated predominantly significant leisure time activity restrictions. Work and school performance were strongest affected in persistent pain disorder, obsessive-compulsive disorders, generalized anxiety as well as recurrent depression.

The frequency and the degree of disabilities and impairments associated with mental disorders in adolescence, seems to be at least as pronounced as in adult mental disorders (Robins \& Regier, 1991; Magee et al. 1996, Wittchen \& von Zerssen, 1987) and is strongly related to comorbidity. About one-third of all cases with pure mental disorders and almost two-thirds of all co-morbid cases were completely disabled for at least 1 day in the past month. The median number of days missed in the past month because of mental disorders went up from four days in those with pure diagnoses to eight days in those with co-morbid conditions. Given the fact that adolescents and young adults, at this time of their life, go through a key phase of socialization in terms of professional career and interpersonal relationships, these numbers indicate from a public health perspective a considerable risk potential for an accumulation of complicating factors and future chronicity.

The substantial burden and suffering that adolescents and young adults with mental disorders experience is also impressively underlined by the finding that almost $50 \%$ of all cases, have contacted a health professional because of their condition, mostly medical doctors, but also psychological services in an unexpectedly high frequency. The general help-seeking rates are relatively similar to those reported in previous studies of adolescents in the US (Cuffe et al. 1995), but unlike to these studies, we find considerable correlation between treatment and diagnostic category (highest rates for panic disorder, generalized anxiety and PTSD). Treatment rates in adolescents are slightly higher than those found for adults in our previous community survey (MFS, Wittchen \& von Zerssen, 1987) and particularly different with regard to the substantially higher rates for use of psychological services (young cohorts, 15\%; older respondents, $3 \cdot 2 \%$ ). We speculate that the more recent expansion of psychological services, the widespread availability of cognitive-behavioural treatments and the more recent complete cover- 
age of psychotherapy costs by the insurance companies are related to this finding. Disorders with relatively high psychologist help-seeking rates: recurrent depressive disorder, PTSD, social phobia, and panic with agoraphobia. For these conditions cognitive-behavioural interventions are strongly recommended in psychiatric text books as well as consensus documents (see Kasper \& Möller, 1995).

The Early Developmental Stages of Psychopathology (EDSP) is a 5-year prospective epidemiological study funded by the German Ministry of Research and Technology to investigate the prevalence of substance use and other mental disorders, their early development and progression, and patterns of co-morbidity. H.-U. Wittchen is the principal investigator. Scientific advisors are Dr J. Angst (Zürich), Dr W. Esser (Mannheim), Dr C. Merikangas (New Haven) and Dr R. C. Kessler (Boston). Collaborating sites and investigators are Dr G. Bühringer (Institut für Therapierforschung, München) and Dr U. John (Medizinische Hochschule, Lübeck). Staff members of the EDSP group are: E. Beloch, E. Garczynski, A. Holly, R. Lieb, A. Perkonnig, H. Pfister, V. Reed, P. Schuster, D. Türk, A. Vossen, and U. Wunderlich.

The authors also appreciate the helpful comments and suggestions of the anonymous reviewers.

\section{REFERENCES}

Allgulander, C. (1989). Psychoactive drug use in a general population sample, Sweden: correlates with perceived health, psychiatric diagnoses, and mortality in an automated record-linkage study. American Journal of Public Health 79, 1006-1010.

American Psychiatric Association (1987). Diagnostic and Statistical Manual of Mental Disorders (3rdedn revised). American Psychiatric Association: Washington, DC.

American Psychiatric Association (1994). Diagnostic and Statistical Manual of Mental Disorders (4th edn). American Psychiatric Association: Washington, DC.

Angst, J. \& Dobler-Mikola, A. (1985). The Zurich study - V. Anxiety and phobia in young adults. European Archives of Psychiatry and Neurological Sciences 234, 408-418.

Bird, H. R., Canino, G., Rubio-Stipec, M., Gould, M. S., Ribera, J., Sesman, M., Woodbury, M., Huertas-Goldman, S., Pagan, A., Sanchez-Lacay, A. \& Moscoso, M. (1988). Estimates of the prevalence of childhood maladjustment in a community survey in Puerto Rico. Archives of General Psychiatry 45, 1120-1126.

Boyd, J. H., Burke, J. D., Gruenberg, E., Holzer, C. E., Rae, D., George, L. K., Karno, M., Stolzman, T., McEvoy, L. \& Nestadt, G. (1984). Exclusion criteria of DSM-III : a study of co-occurrence of hierarchy-free syndromes. Archives of General Psychiatry 41, 983-989.

Boyle, M. H., Offord, D. R., Hofmann, H. G., Catlin, G. P., Byles,

J. A., Cadman, D. T., Crawford, D. T., Links, P. S., Rae-Grant, N. I. \& Szatmari, P. (1987). Ontario child health study. Archives of General Psychiatry 44, 826-831.
Burke, K. C., Burke, J. D., Regier, D. A. \& Rae, D. S. (1990). Age at onset of selected mental disorders in five community populations. Archives of General Psychiatry 47, 511-518.

Chambers, W. J., Puig-Antich, J., Hirsch, M., Paez, P., Ambrosini, P. J., Tabrizi, M. A. \& Davies, M. (1985). The assessment of affective disorders in children and adolescents by semistructured interview: test-retest reliability of the Schedule for Affective Disorders and Schizophrenia for School-Age Children. Present Episode Version. Archives of General Psychiatry 42, 696-702.

Costello, A., Edelbrock, C. Kalas, R., Kessler, M. \& Klaric, S. A. (1982). Diagnostic Interview Schedule for Children (DISC). National Institute for Mental Health: Bethesda, MD.

Cuffe, S. P., Walker, J. L., Cuccaro, H. L., Pumariega, A. J. \& Garrison, C. Z. (1995). Race and gender differences in the treatment of psychiatric disorders in young adolescents. Journal of the American Academy of Child and Adolescent Psychiatry 34, 1536-1543.

Derogatis, L. R., Lipman, R. S. \& Covi, L. (1973). The SCL-90: An Outpatient Psychiatric Rating Scale. Deutsche Bearbeitung CIPS. Psychopharmacological. Bulletin.

Eaton, W. W., Kessler, R. C., Wittchen, H.-U. \& Magee, W. J. (1994). Panic and panic disorders in the United States. American Journal of Psychiatry 151, 413-420.

European Monitoring Centre for Drug and Drug Addiction (1996). Annual Report on the State of the Drugs Problem in the European Union. European Communities: Lisbon, Portugal.

Edelbrock, C., Costello, A. J., Dulcan, M. K., Kalas, R. \& Conover, N. C. (1985). Age differences in the reliability of the psychiatry interview of the child. Child Development 56, 265-275.

Feehan, M., McGee, R., Nada Raja, S. \& Williams, S. M. (1994). DSM-III-R disorders in New Zealand 18 year olds. Australian and New Zealand Journal of Psychiatry 28, 87-99.

Fleming, J. E. \& Offord, D. R. (1990). Epidemiology of childhood depressive disorders: a critical review. Journal of the American Academy of Child and Adolescent Psychiatry 29, 571-580.

Garrison, C. Z., Addy, C. L., Jackson, K. L., McKeown, R. E. \& Waller, J. (1992). Major depressive disorder and dysthymia in young adolescents. American Journal of Epidemiology 135, 792-802.

Hiller, W., Dichtl, G., Hecht, H., Hundt, W. \& von Zerssen, D. (1994). Testing the comparability of psychiatric diagnoses between ICD-10 and DSM-III-R. Psychopathology 27, 19-28.

Kasper, S. \& Möller, H. J. (eds.). (1995). Angst und Panikerkrankungen. Fischer: Jena.

Kessler, R. C., McGonagle, K. A., Zhao, S., Nelson, C. B., Hughes, M., Eshleman, S., Wittchen, H.-U. \& Kendler, K. S. (1994). Lifetime and 12-month prevalence of DSM-III-R psychiatric disorders in the United States: Results from the National Comorbidity Survey. Archives of General Psychiatry 51, 8-19.

Kessler, R. C., Sonnega, A., Bromet, E., Hughes, M. \& Nelson, C. B. (1995). Post-traumatic stress disorder in the National Comorbidity Survey. Archives of General Psychiatry 52, 1048-1060.

Lachner, G., Wittchen, H.-U., Perkonigg, A., Holly, A., Schuster, P., Wunderlich, U., Türk, D., Garczynski, E. \& Pfister, H. (1997). Structure, content and reliability of the Munich-Composite International Diagnostic Interview (M-CIDI). Substance use sections. European Addiction Research (in the press).

Lewinsohn, P. M., Hops, H., Roberts, R. E., Seeley, J. R. \& Andrews, J. A. (1993). Adolescent psychopathology: I. Prevalence and incidence of depression and other DSM-III-R disorders in high school students. Journal of Abnormal Psychology 102, 133-144.

Lewinsohn, P. M., Roberts, R. E., Seeley, J. R., Rohde, P., Gotlib, I. H. \& Hops, H. (1994). Adolescent psychopathology: II. Psychosocial risk factors for depression. Journal of Abnormal Psychology 103, 302-315.

Lewinsohn, P. M., Rohde, P. \& Seeley, J. R. (1995). Adolescent psychopathology: III. The clinical consequences of comorbidity. Journal of the American Academy of Child and Adolescent Psychiatry 34, 510-519.

McGee, R., Feehan, M., Williams, S. \& Anderson, J. (1992). DSM- 
III disorders from age 11- to age 15 years. Journal of the American Academies of Child and Adolescent Psychiatry 29, 611-619.

Magee, W. J., Eaton, W. W., Wittchen, H.-U., McGonagle, K. A. \& Kessler, R. C. (1996). Agoraphobia, simple phobia, and social phobia in the National Comorbidity Survey. Archives of General Psychiatry 53, 159-168.

Merikangas, K., Angst, J., Eaton, W., Canino, G., Rubio-Stipec, M., Wacker, H., Wittchen, H.-U., Andrade, L., Essau, C. A., Kraemer, H., Robins, L. \& Kupfer, D. (1996). Comorbidity and boundaries of affective disorders with anxiety disorders and substance abuse: results of an international task force. British Journal of Psychiatry 168 (suppl. 30), 49-58.

Milne, J. M., Garrison, C. Z., Addy, C. L., McKeown, R. E., Jackson, K. L., Cuffe, S. P. \& Waller, J. L. (1995). Frequency of phobic disorder in a community sample of young adolescents. Journal of the American Academy of Child and Adolescent Psychiatry 34, 1202-1211.

Nelson, C. B., Little, R. J., Heath, A. C. \& Kessler, R. C. (1996). Patterns of symptom progression for DSM III-R alcohol dependence: results from the US National Comorbidity Survey. Psychological Medicine 26, 449-460.

Nelson, C. B. (1995). Prevalence and incidence of alcohol use and DSM-III-R alcohol abuse and dependence. In Temporal Progression of Alcohol Dependence Symptoms: Results from the National Cormorbidity Survey. Ph.D. thesis. Rackham School of Graduate Studies, University of Michigan: Ann Arbor.

Perkonigg, A. \& Wittchen, H.-U. (1997). Traumatic events and DSM-IV post-traumatic stress disorder in adolescents and young adults. In Post-traumatic Stress Disorder: Lifespan Developmental Perspective (ed. A Maercker, M. Schützwohl and Z. Solomon). Hogrefe: Göttingen. (In the press)

Perkonigg, A., Wittchen, H.-U. \& Lachner, G. (1996). Wie häufig sind Substanzmißbrauch und abhängigkeit? Ein methodenkritischer Überblick. Zeitschrift für Klinische Psychologie 25, 280-295.

Pfister, H. \& Wittchen, H.-U. (1995). M-CIDI Computer Program and Diagnostic Algorithms for DSM-IV. Max-Planck-Institut für Psychiatrie, Eigendruck (English), Klinisches Institut: Munich.

Reed, V., Nelson, C. B. \& Wittchen, H.-U. (1997). DSM-IV panic attacks and panic disorder in a community sample of adolescents and young adults. Journal of Psychiatric Research (in the press).

Regier, D. A., Burke, J. D. \& Burke, K. C. (1990). Comorbidity of Affective and Anxiety Disorders in the NIMH Epidemiologic Catchment Area Program. American Psychiatric Press, Inc.: Washington, DC

Resnick, H. S., Kilpatrick, D. G., Dansky, B. S., Saunders, B. E. \& Best, C. L. (1993). Prevalence of civilian trauma and post-traumatic stress disorder in representative national sample of women. Journal of Consulting and Clinical Psychology 61, 984-991.

Robins, J. N. \& Regier, D. A. (eds.). (1991). Psychiatric Disorders in America. The Epidemiologic Catchment Area Study. Maxwell Macmillan International: New York.

Robins, J. N., Helzer, J. E., Crougham, R., Williams, J. B. \& Spitzer, R. L. (1981). NIMH Diagnostic Interview Schedule: Version III National Institute of Mental Health: Rockville, MD.

Wittchen, H.-U. (1994). Reliability and validity studies of the WHOComposite International Diagnostic Interview (CIDI): a critical review. Journal of Psychiatric Research 28, 57-84.
Wittchen, H.-U. (1996a). Critical issues in the evaluation of comorbidity. British Journal of Psychiatry 168 (suppl. 30), 9-16.

Wittchen, H.-U. (1996b). Zwischenbericht 'Vulnerabilitäts und Protektionsfaktioren bei Frühstadien von Substanzmißbrauch und - abhängigkeit.' Internal Report: München.

Wittchen, H. U. \& Pfister, H. (1997). DIA-X Manual: Instruktionsmanual zur Durchführung von DIA-X (M-CIDI) Interviews. Swets \& Zeitlinger: Frankfurt.

Wittchen, H.-U. \& von Zerssen, D. (Hrsg.) (1987). Verläufe behandelter und unbehandelter Depression und Angtstörungen. Springer: Berlin.

Wittchen, H.-U., Hecht, H., Zaudig, M., Vogl, G., Semler, G. \& Pfister, H. (1987). Häufigkeit und Schwere psychischer Störungen in der Bevölkerung - Eine epidemiologische Feldstudie. In Verläufe behandelter und unbehandelter Depressionen und Angsstörungen (ed. H.-U. Wittchen and D. Zerssen von), (pp. 232-251). Springer: Berlin.

Wittchen, H.-U., Burke, J. D., Semler, G., Pfister, H., Cranach, M. von \& Zaudig, M. (1989). Recall and dating reliability of psychiatric symptoms - test-retest reliability of time related symptom questions in a standardized psychiatric interview (CIDI/DIS). Archives of General Psychiatry 46, 437-443.

Wittchen, H.-U., Essau, C. A., Zerssen, D. von, Krieg, D. J. \& Zaudig, M. (1992). Lifetime and six-month prevalence of mental disorders in the Munich Follow-up Study. European Archives of Psychiatry and Clinical Neurosciences 241, 247-258.

Wittchen, H.-U., Beloch, E., Garczynski, E., Holly, A., Lachner, G., Perkonigg, A., Pfütze, E.-M., Schuster, P., Vodermaier, A., Vossen, A., Wunderlich, U. \& Zieglgänsberger, S. (1995a). Münchener Composite International Diagnostic Interview (M-CIDI, Paperpencil and CAPI version 2.2, 2/95, English). Max-Planck-Institut für Psychiatrie, Klinisches Institut (Eigendruck): Munich.

Wittchen, H.-U., Kessler, R. C., Zhao, S. \& Abelson, J. M. (1995b). Reliability and procedural validity of the University of MichiganCIDI DSM-III-R generalized anxiety disorders. Journal of Psychiatric Research 29, 95-110.

Wittchen, H.-U., Zhao, S., Abelson, J. M., Abelson, J. L. \& Kessler, R. C. (1996). Reliability and procedural validity of UM-CIDI DSM-III-R phobic disorders. Psychological Medicine 26, $1169-1177$.

Wittchen, H.-U., Perkonigg, A., Lachner, G. \& Nelson, C. B. $(1997 a)$. The early developmental stages of psychopathology study (EDSP) - objectives and design. European Addiction Research (in the press).

Wittchen, H.-U., Lachner, G., Wunderlaich, U. \& Pfister, H. $(1997 b)$. Test-retest reliability of the computerized DSM-IV version of the Munich-Composite International Diagnostic Interview (M-CIDI). Social Psychiatry and Psychiatric Epidemiology (submitted).

Wittchen, H.-U., Nelson, C. \& Kessler, R. (1997c). Social fears and DSM-IV social phobia in a community sample of adolescents and young adults. American Journal of Psychiatry (submitted).

World Health Organization (1990). Composite International Diagnostic Interview (CIDI). World Health Organization, Division of Mental Health: Geneva.

World Health Organization (1991). International Classification of Disease (ICDI-10). World Health Organization, Division of Mental Health: Geneva. 